\title{
Judgement of Volunteer Competence Among Service Professionals: Stereotypes or Skills?
}

Author 1 (corresponding):

Name: Ulrich Thy Jensen

Affiliation 1: School of Public Affairs, Arizona State University, United States

Affiliation 2: Crown Prince Frederik Center for Public Leadership, Aarhus University, Denmark

Email: ujensen@asu.edu

Postal address: 411 N. Central Ave., Suite 480, Phoenix, AZ-85004, United States

Author 2:

Name: Mette Kjærgaard Thomsen

Affiliation: Department of Political Science and Public Management, University of Southern Denmark, Denmark

Email: mtho@sam.sdu.dk

Postal address: Campusvej 55, 5230 Odense M, Denmark 


\title{
Judgement of Volunteer Competence Among Service Professionals: Stereotypes or Skills?
}

\begin{abstract}
While public service professionals may rely on stereotypes and social categories in exercising who gets what, when and how in clientelist citizen-state interactions, it remains unclear whether negative judgements similarly pervade in settings where citizens help produce-rather than consume-public services. We propose that service professionals judge volunteers as incompetent based on (1) a lack of the skills necessary to solve specific tasks, and/or (2) negative stereotypes towards volunteers as a means of shielding the privileged position of the profession or safeguarding the quality of services. Using an experiment among 817 nursing home professionals, negative judgements of volunteer competence were invoked simply by priming professionals to think of citizens volunteering in service production. The effect, however, is not conditional on the type of task (complementary vs. core) solved by volunteers, suggesting that judgments of competence mainly stem from stereotypes of volunteer (in)competence in assisting with service production.
\end{abstract}

Cite as*:

Jensen, U. T., \& Thomsen, M. K. 2022. Judgement of Volunteer Competence Among Service Professionals: Stereotypes or Skills?. Online before print in Public Administration Review. https://doi.org/10.1111/puar.13460.

*This is the accepted version, and content may therefore not perfectly represent the published version. Please consult the published version at: https://doi.org/10.1111/puar.13460. 


\section{Judgement of Volunteer Competence Among Service Professionals: Stereotypes or Skills?}

\section{Evidence for Practice}

- Service professionals can hold negative judgments of volunteers' competence because volunteers lack the skills required to successfully perform a certain task or based on negative stereotypes towards volunteers.

- Negative stereotypes of volunteer competence can prevail among service professionals out of a concern for protecting the privileged position and monopoly of the professional group or out of a concern for the quality of the public services

- Managers can take several steps to counteract negative stereotypes towards volunteers such as articulating how volunteers are valued and can help the organization achieve its mission, as well as using volunteer management practices to ensure volunteers are properly trained to solve specific tasks. 
Scholarship describes how public service professionals-or "street-level bureaucrats"-rely on stereotypes based on social categories in their decision-making (Keiser, Mueser, and Choi 2004; Lipsky 1980; Maynard-Moody and Musheno 2003), and to classify citizens as deserving of help and services (e.g., Harrits 2019; Jilke and Tummers 2018). Yet, it is less clear whether negative stereotypes of citizens similarly prevail among service professionals when citizens volunteer their time and assistance to help produce-rather than act as clients who consume-public services. Early voices alluded to this issue, noting that professionals may hold stereotypical perceptions or inaccurate views of volunteers (Brudney 1990, 72-73); in part invoked by or linked to the strategic response by professional groups or unions in anticipation of labor substitution (Brudney 1990, 32$33)$.

This is problematic as governments around the world are seeking to cultivate volunteer programs to better engage civil societies in service production and provide high-quality services in times of scarce financial resources. "Good" volunteer-staff relationships are at heart of successful volunteer arrangements (Nesbit et al. 2016), but negative attitudes among service professionals towards volunteers and their competence (Brudney 1983) might make service professionals more reluctant to actively collaborate with volunteers (Brudney 1990; Brudney and Gazley 2002; Percy 1984), and make volunteers feel less welcomed, accepted and appreciated (Nesbit et al. 2018). As noted by Brudney "without question, the most serious impediment to a successful volunteer program is the likely indifference or, worse, outright opposition of regular personnel to volunteers." $(1990,33)$.

It is thus critical, not only to explore whether service professionals hold negative judgments of volunteers' competence, but to understand the origins of such stereotypes. We contribute to these important issues by answering two questions: Do service professionals view volunteers as incompetent? And if so, are such judgements of competence a function of (1) volunteers lacking the 
necessary skills to solve specific tasks since they do not possess the specialized, theoretical knowledge and professional norms required for certain tasks, or (2) negative stereotypes among service professionals as a strategic response to shield the privileged position of their occupational group and safeguard the quality of public services?

We test these two possible explanations using a vignette experiment embedded in an electronic survey to 817 nursing home professionals in Denmark. As part of the survey, nursing home professionals were randomly assigned to one of three conditions. In two conditions, which act as our treatments, nursing home professionals were primed to think of volunteers solving a "core" or a "complementary" task. Our third group did not receive any priming stimuli and acts as our baseline group. Including a "core" and a "complementary" task vignette allows us to identify whether professionals' judgement of volunteer competence is a function of negative stereotypes of volunteer competence or based on volunteers' actual skills.

Our findings indicate that nursing home professionals exposed to either of the two vignettes provide lower average ratings of volunteer competence compared to our baseline group of professionals who received no prime. Moreover, judgements of volunteer competence among our two treatment groups are indistinguishable; suggesting that volunteers are viewed as no less competent when they are portrayed to solve simple, straightforward tasks compared to complex service tasks requiring specialized, theoretical knowledge for their successful execution. Together this suggests that professionals' judgement of volunteer competence mainly stems from negative stereotypes of volunteer competence.

These findings are important as they point to a need for organizations and managers to take steps to reduce and prevent the formation of negative stereotypes of volunteers. One step proposed in the existing literature is to convey a positive view of volunteers by articulating how volunteers provide valuable inputs to achieving the organizational mission and serving core clientele (Kray and 
Shirako 2012). Another often-mentioned step is to ensure good volunteer management practices, including proper training to ensure volunteers have the necessary skills and competencies to assist with organizational tasks (Hager and Brudney 2004; Rogelberg et al. 2010).

Next, we outline how service professionals' negative stereotypes of volunteer competence might manifest and how they can emerge partly as a strategic response from professionals to shield the privileged position of their profession and as a means to safeguard the quality of public services. We then review our research design, including the construction of experimental vignettes, data collection and measurement of the dependent variable. Finally, we present our main findings before concluding with a discussion of the study's central limitations and implications.

\section{Theoretical Framework}

According to psychology research, people use two trait dimensions to judge people and groups: Warmth and competence. Warmth can be defined as "traits that are related to perceived intent, including friendliness, helpfulness, sincerity, trustworthiness and morality ..." whereas competence reflects "... traits that are related to perceived ability, including intelligence, skill, creativity and efficacy." (Fiske, Cuddy, and Glick 2007, 77). Prior research shows that judgements of warmth are often made more rapidly compared to judgments of competence (Fiske et al. 2007). The weight or importance we assign to each of these two traits, however, is context-specific. Judgements of competence, for instance, may be more important in a job hiring situation (Cuddy, Fiske and Glick 2007), since the primary concern relates to matching the needs of a particular job description to the specific skills of the applicant.

Stereotypes are oversimplified mental images of some category of a group shared by multiple individuals (Bullock and Stallybass 1977). Judgements of warmth or competence may-at least in part-stem from stereotypes based on social categories (e.g., gender, race, ethnicity, religion 
or socioeconomic status), and affect whether other people are judged as warm $v s$ cold or competent $v s$ incompetent. Misjudgments of out-group members' competence can have severe consequences. According to the "Stereotype Content Model" (SCM), which has been validated in several cultures, different combinations of these two dimensions may result in different emotions (or prejudices)admiration, contempt, envy and pity-towards the stereotyped groups. Stereotyped groups that are perceived as cold but competent, may elicit envy, whereas stereotyped groups that are perceived as warm but incompetent, may elicit pity (Fiske et al. 2002). For example, elderly or disabled people who are often perceived as warm but incompetent often elicit pity because of the assumption that their situation is beyond their own control (Cuddy et al. 2011). An extension of SCM-called Behaviors from Intergroup Affect and Stereotypes (BIAS)-argue that warmth and competence judgements also shape people's behaviors (e.g., helping, harassing, convenient cooperation and neglecting) towards the stereotyped groups (Cuddy et al. 2011).

These insights from psychological science into stereotypes have also been applied to public administration research. For instance, public sector employees have sometimes been viewed as incompetent, cold, lazy or bureaucratic by citizens (Baldwin 1990; de Boer 2020; Rölle 2017; Van de Walle 2004). In other research, negative stereotypes about the public sector more generally have been shown to negatively affect how citizens judge public sector performance (Marvel 2016). Recently, a few studies have also revealed negative stereotypes and discrimination targeting citizens in citizen-state interactions where clients consume public services. For example, clients' race and social class have been shown to matter for how service professionals assess clients' deservingness of help (Harrits and Møller 2014; Jilke and Tummers 2018). The salience and activation of these stereotypes, however, may depend on the environmental context. Race-based stereotypes, for example, were used less following a reduction in professionals' workload (Andersen and Guul 2019), while class-based stereotypes are used more frequently when professionals work in very 
heterogenous communities or when professionals and clients belong to markedly different social classes (Harrits 2019).

However, the existing application of insights into stereotypes have focused almost exclusively on the "demand side" (i.e., how citizens as clients view bureaucracies and the people that staff them) or framed as heuristics used by professionals to regulate who gets what, when, and how. Little attention has been paid to the role stereotypes plays on the "supply side", that is, whether public service professionals hold negative stereotypical views of citizen attributes when citizens volunteer their time and effort to help produce-rather than consume-public services. This is important because many public organizations rely on or seek to cultivate coproduction initiatives to engage civil societies (Alford 2009; Bovaird 2007; Parks et al. 1981). Citizens, for example, may coproduce educational services by assisting a teacher with practical tasks in the classroom, or coproduce health and care services by organizing social events for elderly residents at nursing homes. However, negative stereotypes and alienating attitudes towards volunteers among service professionals might make professionals more reluctant to work with volunteers (Brudney 1990; Brudney and Gazley 2002), leading to a hostile environment in which volunteers do not feel welcomed, accepted and appreciated (Nesbit et al. 2018). While much of the existing research on stereotypes and prejudices focus on demographic characteristics such as age, gender, race, ethnicity, religion or socioeconomic status, we argue that occupations might demark equally important discrete categories for in- and out-groups in professionalized settings.

In his now famous case study of the profession of medicine, Friedson (1988) describes how doctors managed to "elevate social prestige by restricting who can practice in what it designates as the medical forum" (Morrall 2001, 86). To assert occupational control over certain domains and services, professions seek to "close itself" to competing groups. In the case of medicine, these efforts include restricting services on the basis of esoteric knowledge, skills and credentials; as for 
instance is the case when nurses are fought off from acts of bodily examinations or prescriptions of drugs to patients. Similar examples can be found in the context of schools (e.g., teachers' aides vs. schoolteachers), but can also be extended to non-traditional organizational actors such as volunteers or citizens engaged in coproducing public services. Following the "neo-Weberian" and "functionalist" perspectives from the sociology of professions literature, service professionals can be expected to use "belonging to occupation" as a social category to extrapolate general perceptions of competence to members of their group (i.e., other service professionals) vs. incompetence to people who are outsiders to the group (i.e., volunteers), irrespective of the individuals' actual skills as a way to assert occupational control over service tasks. While "neo-Weberians" would ascribe this kind of social closure behaviors to an extrinsic, egocentric motive to shield the privileged position of the occupational group and maintain its privileged position and monopoly, "functionalists" would cast the very same behavior as based on an altruistic desire to safeguard and maintain high-quality of services to beneficiaries. Regardless of the underlying motive, the outcome is the same: Negative stereotypes of volunteer competence prevail to help demark the in-group (professionals) from the out-group (volunteers).

We focus on negative stereotypes of volunteer competence among service professionals for two reasons. First, existing research on volunteerism (Clary et al. 1998) suggests that altruistic motivation (i.e., the desire to help others) is one of the most salient motivations underlying volunteerism. Thus, we expect volunteers as a group to be uniformly perceived as warm by most people. On the other hand, the extent to which volunteers as a group are perceived as competent is much less clear. This may depend on a number of factors such as individuals' demographic characteristics (Fiske 2018), and naturally, volunteers' actual skills. Second, professionals' perception of volunteer competence likely plays a key role in establishing successful collaborations (Nesbit et al. 2016). If volunteers are perceived as incompetent-irrespective of whether it stems 
from negative stereotypes of volunteers-service professionals likely will not value volunteers' inputs or see volunteers as worthy of their time and efforts.

So, what may determine whether volunteers are judged as incompetent? We propose that such judgments can originate from two sources. First, volunteers may lack the necessary skills to solve specific tasks because they do not possess the specialized, theoretical knowledge and professional norms shared by members of the profession. Specialized knowledge means that "only members of the profession are in possession of this knowledge", while theoretical knowledge refers to "a general understanding of relevant concepts and causal relationships within the field" (Andersen and Pedersen 2012, 47). Professional norms prescribe which "actions are required, prohibited, or permitted in a specific situation" (Andersen and Pedersen 2012, 48). Second, even if volunteers possess the necessary skills, negative judgments of volunteer competence may still prevail. This can be due to a desire among service professionals to protect the privileged position of their profession or safeguard the quality of services, triggering negative stereotypes of volunteer competence as a means to "keep out" volunteers and maintain a monopoly on service tasks. The protection of the profession may-in part-be unconscious, that is, service professionals unconsciously associate out-groups (here: volunteers) with negative attributes such as incompetence. Such unconscious attitudes may be a result of the socialization, environment and culture individuals are exposed to (for a discussion of unconscious attitudes, see Marvel 2016). Other times, these perceptions might be invoked by or linked to strategic responses by professional groups or labor unions in anticipation of labor substitution (e.g., when contracts are used to block the involvement of volunteers in particular areas or for certain tasks, Brudney 1990, 32-33).

To empirically disentangle whether service professionals' judgment of volunteer competence stems from volunteers' actual skills or negative stereotypes, we can (1) use priming techniques and (2) take advantage of the important distinction between core and complementary 
tasks. On the latter, Brandsen and Honingh (2016) note that citizens, service users and volunteers may assist with different tasks in the service production phase: Core and complementary tasks. Core tasks are “... part of the organization's core services" (Brandsen and Honingh 2016, 432). In the context of nursing homes, for example, an empirical study shows that health assistants classify assisting elderly residents with personal care and hygiene as core tasks, whereas accompanying elderly residents to the hairdresser, with leisure activities or with shopping are all classified as complementary tasks (Thomsen and Jensen 2018). Consequently, solving core tasks-in contrast to complementary ones-requires specialized, theoretical knowledge and professional norms, which are also the defining features of a profession (Andersen and Pedersen 2012; Friedson 2001).

Similar to existing social psychology research (e.g., Rohmer and Louvet 2018), we study stereotypes using priming technique. According to priming theory, people use shortcuts and heuristics when faced with a judgment or choice. As a result, they rely upon information that comes to mind spontaneously and effortlessly (Krosnick and Kinder 1990). Research has shown when people (e.g., service professionals) are primed to think of a certain group (e.g., volunteers) performing a given task (e.g., assisting with a specific service task), judgments of the group is impacted by the information associated with the construct being primed (Jamieson and Harkins 2011).

Priming service professionals to think of volunteer involvement, it is important to distinguish between the type of task (complementary vs. core) volunteers can help solve. If service professionals base their judgement of volunteers competence on volunteers' actual skills and negative stereotypes, we would expect to observe two patterns: (1) professionals primed to think of volunteers solving a specific task will judge volunteers as less competent compared to professionals receiving no prime stimuli, and (2) professionals primed to think of volunteers solving a complementary task will judge volunteers as more competent compared to professionals primed to 
think of volunteers solving a core task (because core tasks require specialized, theoretical knowledge and professional norms that are only shared by members of the profession).

By the same notion, if service professionals base their judgement of volunteer competence solely on negative stereotypes about volunteers as generally incompetent and incapable-and not on volunteers' actual skills-we expect to observe that (1) professionals primed to think of volunteers solving a specific task will judge volunteers as less competent compared to professionals receiving no prime stimuli and (2) professionals primed to think of volunteers solving a core task or a complementary task will judge volunteers as equally (in)competent. In the next section, we describe how our research design disentangles these different antecedents of service professionals' judgement of volunteer competence.

\section{Research Design and Data}

Examining service professionals' stereotypical perceptions of volunteer competence is a task fraught with challenges. One hurdle is potential confounders. If we simply ask professionals to assess volunteers' competence in a given volunteer context, their perceptions are likely colored by the type of tasks volunteers assist with, experiences with volunteers, and other characteristics of the professional him or herself. One way for researchers to tackle this challenge is to conduct an survey experiment in which service professionals are primed to either think of volunteers solving a specific task or given no priming stimuli. Afterwards, service professionals are asked to judge volunteer competence. We adopt this approach by randomly assigning service professionals to one of three priming conditions. Subsequently, respondents were asked to assess volunteers' competence. The exact construction of the experimental conditions is described below.

\section{Construction of Experimental Conditions}


Our study included three experimental conditions. In two of the conditions, service professionals were given short vignettes and primed to think of volunteers solving either a "core" task or a "complementary" task. The third group-the baseline group-did not receive any priming stimuli, but only a very short introductory text. The scenarios in our vignettes concern Danish nursing home professionals collaborating with volunteers on the production and delivery of services to elderly residents living at a nursing home facility. We chose this case for two reasons. First, although it is common across a range of public sector service areas to recruit and involve volunteers to assist in the delivery of services in Denmark, the scope of volunteer involvement in nursing homes exceeds that of other large welfare service areas such as education and health care (FOA 2016). In a 2016 survey, 80 percent of health assistants reported that volunteers perform various tasks (FOA 2016). Second, volunteers assisting at public nursing homes take on an increasing number and variety of tasks (FOA 2016). An important part of this development is that volunteers solve a portfolio of tasks that encompasses tasks perceived by professionals as "core" and "complementary", enabling us to create realistic vignettes for both treatment conditions.

Existing research shows that many volunteers are driven by altruistic motivation (Clary et al. 1998), and this is also the case in a Danish setting. A Danish study shows that eight out of ten volunteers are driven by altruistic motivation and that nine out of ten volunteers at Danish nursing homes are 60 years old or older and have retired from the labor market (Aarhus Municipality 2016). In combination with the notion that previous research on stereotypes shows that elderly people as $a$ group is often perceived as warm (Fiske 2018), we argue that any negative stereotypes of volunteers among nursing home professionals likely exist and manifest along the competence dimension. Consequently, we focus on this dimension for our empirical study.

As noted above, three experimental conditions are needed to disentangle whether service professionals' judgement of volunteer competence is a function of stereotypes and/or volunteers' 
actual skills. If negative stereotypes prevail, our study should reveal a lower group mean difference in the judgement of volunteer competence among professionals primed to think of volunteers solving a specific task in contrast to no priming stimuli (baseline group). However, to identify whether judgements of competence are also a function of volunteers' actual skills, we need to induce variation in the type of task solved by volunteers. In both vignettes, nursing home professionals were primed to think of volunteers assisting during mealtime. The two vignettes are thus identical except for one thing. In one vignette (condition), volunteers were portrayed as table hosts entertaining and chatting with the elderly residents. In the other vignette (condition), volunteers were described as actively assisting elderly residents consuming their meals. While this difference might seem subtle, it is extremely important as it captures a key distinction between “complementary" tasks that are straightforward to execute and require no specialized, theoretical knowledge such as chatting with another person, and "core" tasks that are complex and necessitate professional skills and specialized, theoretical knowledge for their successful execution. If judgements of volunteer competence are (also) a function of volunteers' skills, we should expect volunteers' competence to be evaluated higher when they perform a complementary task in contrast to a core task. On the contrary, if volunteers are not judged as more competent when they perform a complementary task although such tasks are straightforward to execute and require no specialized, theoretical knowledge, then nursing home professionals' judgement is mainly a function of negative stereotypes. The exact wording of experimental conditions is presented in figure 1, with text in bold emphasizing the priming information.

[Figure 1 about here] 
The vignettes were developed based on interviews and a pilot survey with nursing home professionals. Our pilot survey reveals that 91 percent categorized "serving food and assist with eating" as a core task (Thomsen and Jensen 2018; see also Thomsen and Jensen 2020). In interviews, nursing home professionals qualitatively confirmed this observation, noting that expertise on how to feed elderly with chewing and swallowing difficulties is required to guarantee the safety of the resident. According to the respondents, only nursing home professionals possess the skills and specialized knowledge to safely assist elderly residents during mealtime and to respond appropriately in cases of emergencies where residents choke on their food. While it is clear that nursing home professionals view assisting elderly residents with eating their meals as a core professional task, results from another study conducted in Aarhus Municipality, shows that 14 percent of the respondents, that had been in contact with volunteers within the last month, reported that volunteers indeed assist with "serving food and eating", making the "core" task scenario realistic.

\section{Data Sources and Sample}

Prior to the data collection, we conducted a power analysis using the program "Optimal Design" to help determine the desired sample size. While we were not able to identify previous studies to help guide us on expected effect sizes, approximately 900 subjects across three groups would be sufficient to detect an average treatment effect of 0.22 standard deviations at 80 percent power and an alpha level of 5 percent. With this target in mind, we distributed an electronic survey in collaboration with the largest labor union in Denmark, FOA, among members of their web panel. FOA members represent a wide array of public sector service areas in Denmark, and we therefore restrict our subsample to nursing home professionals. We focus on the single largest group of 
employees at Danish nursing homes: Health assistants (Ministry of Health 2016). The majority of health assistants in Denmark are employed at public nursing homes (which account for $~ 85 \%$ of all nursing homes in Denmark, cf. Rostgaard et al. 2016).

Health assistants fit the criteria of a profession (Andersen and Pedersen 2012; Friedson 2001) as they complete theoretical and practical training related to various care tasks and services. On this basis, health assistants obtain a shared base of specialized, theoretical knowledge and are socialized to professional norms about appropriate conduct when caring for elderly residents. Health assistants either hold 19 or 39 months of education, with the latter group completing an added 20 months to the "short" education. Health assistants, regardless of length of education, have received training in tasks related to personal care, practical help, nutrition and rehabilitation (Ministry of Health 2016). Health assistants with a "long" education have also received in training in administration of medicine (Ministry of Health 2016). Thus, health assistants working at nursing homes, regardless of length of education, share many of the same job duties.

The electronic survey was distributed in February of 2018. Besides data from our electronic survey, our study also included data om demographic characteristics (age, gender, education and region) obtained from FOA's web panel. Data from these two data sources were merged via a personal identifier. Table A-1 in the Appendix provides an overview of variables and data sources. The survey yielded a total response rate of 39.4 percent. One reminder was sent out to increase the response rate. To ensure that the vignette scenarios were relevant and realistic to respondents, the survey experiment only included health assistants who reported that they worked at a nursing home, and that volunteers assist with service tasks at their workplace. The latter requirement brings the number of respondents down from 1,260 to 971 ( 77 percent). Our analytic sample was further reduced to 817 respondents, since some respondents had missing information on the outcome items 
(cf. Table A-2 in the Appendix) or demographic characteristics from FOA's web panel (cf. Table A-1).

Members of FOA self-select into the web panel. As a result, it is important to compare our analytical sample with the broader population of health assistants working at nursing homes in Denmark. While we do not have population-level information on all health assistants, we can compare our analytic sample to the subgroup of the population of health assistants working at nursing homes who were a member of FOA in 2018. Since FOA is a major labor organization, it organizes a large part of health assistants in Denmark. We do not find any evidence of systematic differences in terms of gender and age between our sample and the FOA subpopulation of health assistants (cf. Table A-3 in the Appendix). We also note that our sample shows considerable variation along respondents' characteristics such as gender, age, and geographical location.

\section{Outcome Measure}

Our dependent variable captures nursing home professionals' judgement of volunteer competence related to assisting elderly residents. The items were developed for the purpose of this study, and were pre-tested in our pilot survey. Prior studies on stereotypes have measured competence by asking respondents to rate how competent they believe a given group (e.g., the elderly) are as perceived by the broader population (e.g., Americans) (see for example Cuddy et al. 2007; Fiske et al. 2002). To ensure that nursing home professionals did not adopt heterogenous interpretations of "competence", we asked them to judge volunteer competence in relation to specific situations (e.g., helping the elderly, accommodate the needs of the elderly, and assessing abilities of the elderly). The specific reference points were inspired by our interviews with nursing home professionals in which they expressed concerns about volunteers not always being able to accommodate the elderly's need and having difficulties with assessing elderly's abilities. We did not ask the 
respondents to judge how volunteers are perceived by Danes in general, but how they themselves would judge volunteer competence.

Our outcome measure consists of three items operationalized on a 5-point Likert scale, ranging from completely agree to completely disagree. The items were worded as follows: "Most volunteers are competent in helping the citizens"; "volunteers are able to accommodate citizens' needs"; and "volunteers often have difficulties assessing citizens" abilities". An exploratory factor analysis (principal factor) reveals factor loadings of 0.80 and 0.82 for the first two items, and 0.45 for the third and reversely coded item (see Table A-2 in the Appendix). It is common to see lower factor loadings for reversely coded items, but it serves the important function to help reduce response set. We therefore retain all three items for further analysis. The factor analysis yields one factor with an Eigenvalue above 1, supporting the all three items load onto a single latent factor. Items are also internally consistent with a Cronbach's alpha score of 0.74 , exceeding the commonly imposed threshold of 0.70 . On this basis, we generated a summative index giving equal weight to each item. Prior to generating the index, we reversed the coding of the third item to ensure similar directionality of all items. Finally, the index was rescaled to range from $0-10$, with 10 expressing perception of maximum competence.

\section{Validation of Experiment}

An important prerequisite for valid conclusions of our experimental design is successful randomization of subjects to conditions. The random assignment to experimental condition creates, in expectation, comparability between groups of subjects. Thus, nursing home professionals assigned to the baseline group should on average "look the same" as nursing home professionals assigned to either the "complementary" or "core" task vignette. While this assumption is difficult to validate empirically as we cannot accurately measure all relevant demographics and attributes of 
subjects, our covariates can offer some indications. Table 1 reports group means on all our covariates across our three conditions. Although female subjects seem to be slightly underrepresented in the "core" task condition, differences in group means are generally indistinguishable. F-tests indicating that treatment indicators are jointly zero cannot be rejected for all covariates with exception for gender. This bolsters our confidence that the random assignment to treatment was successful and created, in expectation, identical groups across experimental conditions at the outset.

[Table 1 about here]

\section{Results}

This section reports the results for our two questions: Do nursing home professionals view volunteers as incompetent? And if so, are such judgements of competence a function of volunteers' actual skills and/or negative stereotypes?

If we first focus on professionals' view of volunteers as competent or incompetent, we note means of 4.97 for professionals assigned to the core task vignette, 5.14 for professionals assigned to the complementary task vignette, and 6.04 for professionals assigned to the baseline group; all on a scale from 0 to 10 . Since the 263 nursing home professionals assigned to our baseline group received no prime at all, this group, arguably, best reflects the common or average view of volunteer competence. The mean of 6.04 among the baseline group suggests that nursing home professionals view volunteers as moderately competent to assist at nursing homes.

In the absence of a specific task prime, professionals not only, on average, see volunteers as moderately competent but also display considerable variation in their judgement of volunteers' competence (standard deviation of 1.99). If such assessments are a function of volunteers' actual 
skills, we would thus expect variation in judgments of volunteer competence to systematically covary with our two vignette scenarios. On the other hand, if negative stereotypes prevail among service professionals, volunteers' competence might not be evaluated as higher even when they perform complementary tasks that are straightforward to execute, require no specialized, theoretical knowledge and entail little to no complexity. To assess this, and answer our second question, we need to conduct statistical tests comparing the mean ratings of volunteer competence across our three experimental conditions.

As noted above, the means for our three groups are 4.97 (core task vignette), 5.14 (complementary task vignette), and 6.04 (baseline). Each of these can be extracted and derived from Model 1 in Table 2. The constant (or "reference category") represents the mean ratings of volunteer competence among the baseline condition, while OLS regression estimates for the core and complementary vignette conditions denote the group mean difference to the baseline group (i.e., the average treatment effects). Table 2, Model 1 shows that professionals exposed to the core task prime, on average, rate volunteer competence 1.070 scale points lower compared to the baseline group $(p<0.001)$. An almost identical result emerges for professionals exposed to the complementary task prime who, on average, rate volunteer competence 0.903 scale points lower compared to the baseline group $(p<0.001)$. These results are robust when including covariates (cf. Table 2, Model 2), and represent fairly large effect sizes with effects of 0.488 (core task prime) and 0.412 (complementary task prime) of a standard deviation change in our outcome variable (cf. Table 2, Model 3). ${ }^{1}$

[Table 2 about here] 
Finally, we compare the means for our two treatment conditions-the core task vignette and the complementary task vignette. Recall, that the complementary task vignette depicts a mundane, straightforward task that requires no specialized, theoretical knowledge and entails little complexity. In contrast, the core task prime highlights a complex professional task that necessitates the codified, specialized, theoretical knowledge shared by members of the professional group. Hence, if professionals "penalize" volunteers for not possessing the required skills to complete specialized tasks, we would expect professionals exposed to the core task vignette to display markedly lower ratings of volunteer competence compared to professionals exposed to the complementary task vignette. However, we note only a small difference in means between our two treatment conditions: 0.17 (standard error $=0.18, p=0.36$ ). This suggests that nursing home professionals are no less likely to view volunteers as competent when volunteers perform straightforward tasks that require no professional expertise compared to a scenario in which volunteers solve a complex, professional task. Taken together, these findings thus suggest that professionals' judgement of volunteer competence mainly stems from negative stereotypes of volunteer competence rather than the implied (mis)fit between the actual skills of volunteers and those required for the service task.

\section{Discussion and Conclusion}

Volunteers give their time, energy, and devotion to assist professionals in the production of public services to the benefit of service users, their communities and society at large. So, how come despite the popular rhetoric about the benefits volunteers bring to the table, many public and nonprofit organizations circumscribe their contributions or eschew volunteer involvement altogether? (Nesbit et al. 2018, 502). Our study suggests that, at least part of, the answer to this conundrum lies in the underexplored area of public service professionals' attitudes towards 
volunteers. At heart of productive volunteer arrangements lies good volunteer-staff relationships (Nesbit et al. 2016), but as we have highlighted professionals might hold or form negative stereotypical views on volunteers' competence that, in turn, might undercut the very efforts to cultivate volunteer involvement. Our findings thus provide evidence to the model presented in Nesbit, Christensen, and Brudney (2018) who theorize that staff receptivity is a key "nurturing" factor among the organizational characteristics that predict volunteer involvement.

However, rather than "nurturing" and fostering strong staff-volunteer relationship, we show that the professional logics guiding the motives of many occupational groups, dominating the workforces across public service organizations (Mosher 1968), can also operate in rational manners to "squash" such efforts. Drawing on the literature of the sociology of professions (Friedson 2001; Robert and Dietrich 1999), we outline two competing logics for why service professionals consciously-or subconsciously-engage in activities that close the professional domain over tasks and services to members off to out-groups such as volunteers. Professionals may cast volunteers as incompetent to solve service tasks as a means to protect the status of their group by retaining a monopoly on specific tasks. Professionals can also engage in social closure out of a concern for the quality of public services and as a means to safeguard standards that can only be upheld by individuals who share the specialized, theoretical knowledge and professional norms codified by members of the profession. Albeit reflecting different motives and assumptions about human nature, these perspectives both hold long-standing traditions in the sociology of professions and beyond (Robert and Dietrich 1999). It is therefore particularly interesting and puzzling that professionals in our study do not ascribe greater assessments of competence to volunteers when volunteers are portrayed to solve straightforward, mundane tasks that require no specialized, theoretical knowledge. How can this be? 
Prior studies suggest that the formation and activation of stereotypes might depend on contextual environmental conditions (Andersen and Guul 2019; Harrits 2019). Perhaps, professionals who have extensive experience with volunteers or frequent contact with volunteers are less prone to form negative views on volunteer competence. Contact theory (Allport 1979), for instance, purports that lack of contact with an out-group (in this case: volunteers) may cause individuals to resort to negative stereotypes. On the other hand, frequent contact may help demystify out-group members, allow for the creation of reciprocal, trusting relationships, and provide a continuous purview into the tangible benefits volunteers bring to the organization. While we cannot distinguish between professionals' positive and negative experiences with volunteers, we did conduct an exploratory analysis to see whether treatment effects were heterogenous along professionals' frequency of contact with volunteers. As part of our survey, we asked health assistants how often they had been in contact with volunteers within the last month. Collapsing the following response categories: "every day," “3-4 times a week," “1-2 times a week” to mark "frequent contact", and "2 times a month," “once a month," "I haven't been in contact with volunteers at my workplace within the last month" and "don't know" to mark in "infrequent contact.", we find no evidence that frequent contact leads professionals to provide more positive assessments of volunteer competence across the experimental conditions. ${ }^{2}$

This suggests that stereotypes are not necessarily formed by the frequency of contact with volunteers, but perhaps rather by the quality of such relationships. If this is the case, it points to the important steps managers should consider taking to help cultivate good staff-volunteer relationships. Managers can make tangible efforts to support volunteer programs in public organizations (Ellis 2010), for instance, by employing volunteer management practices such as proper screening, training and feedback to volunteers (e.g., Hager and Brudney 2004; Rogelberg et al. 2010). Such efforts may help spur the skill-building that is needed for volunteers to successfully 
assist with service tasks. Unfortunately, we have limited information about the use of specific volunteer management practices in our study (cf. Table A-4.1-2 in the Appendix), and we are therefore unable to test whether negative stereotypes towards volunteers are less likely to be formed and activated in organization with adequate volunteer management practices.

Characteristics of the work environment such as high workloads might also affect formation and activation of stereotypes among service professionals. In a study of discrimination in school settings, for example, Andersen and Guul (2019) note how prejudices and discrimination might be amplified as a way to cope with high workloads. However, rather than amplifying negative stereotypes, job demands such as high workloads or demanding tasks might create greater awareness and recognition of volunteers' contributions to the organizations, and how these can help alleviate part of the burden placed on professionals by high job demands. While we are unable to provide a comprehensive assessment of the potential role of work environmental factors, we did ask health assistants the extent to which they agreed with the following two statements reflecting workload: "do you have sufficient time to perform your work satisfactorily?", and "is it necessary to work at a fast pace?". An exploratory analysis shows no evidence that health professionals in our sample assess volunteer competence differently across the experimental conditions depending on their everyday workloads. ${ }^{3}$ Since workload only represents one salient aspect of professionals' work environment, future research might do well to explore whether volunteer management programs and other conditions of professionals' work environment can exacerbate or reduce the use of negative stereotypes towards volunteers among service professionals.

\section{Limitations}

As with any study, ours comes with a number of limitations that the reader should consider when interpreting its findings and conclusions. According to psychologists, stereotypical images often fall 
along two dimensions: Competence and warmth. Since we only explored the former, it would be interesting for future research to also investigate whether volunteers are viewed as warm or cold, as well as how perceptions of warmth may interact with perceptions of competence.

A second limitation lies in our specific focus on testing whether service professionals use stereotypes towards volunteers, but not exploring in depth-theoretically or empirically-what may exacerbate or reduce the use of stereotypes. As discussed above, the use of volunteer management practices and aspects of the work environment may serve as "triggers" or means for reducing the use of negative stereotypes towards volunteers among service professionals. Research into these topics therefore seems particularly fruitful for future work aiming to better understand the conditions under which negative stereotypes towards volunteers are formed and activated.

Third, one might question the hypothetical nature of our vignette scenarios. While the vignettes depict fictional scenarios, we took several steps to improve the mundane realism of our experimental treatments. First, we limited our study to only include service professionals who worked at a nursing home in which volunteers assist with service tasks. Second, we carefully selected the core and complementary tasks and crafted corresponding vignette descriptions based on qualitative interviews with nursing home professionals and policy reports conducted by the professionals' labor union, FOA. Furthermore, we selected two tasks that revolve around the same situation-mealtime-to keep constant the diversity of tasks performed in nursing homes.

Finally, our study has limitations pertaining to the generalizability of findings. Professions can be characterized by various levels of professionalism based on factors such as the degree of specialized, theoretical knowledge and firmness of professional norms tied to service tasks. One might therefore wonder whether judgments of volunteer competence would be less adverse in contexts characterized by higher professionalized services where volunteers might be less likely to be perceived as a threat to professionals' domain or the quality of services. Examples could include 
citizens volunteering to help provide directions to patients and their relatives as they enter large hospital campuses, or volunteers helping to organize extra-curricular activities in educational institutions. To mitigate some of these issues, we presented vignettes that depicted professionalized services requiring theoretical, specialized knowledge for the successful execution and rudimentary tasks that can be solved by any individual. It is also worth noting, that we only focused on public nursing home, not privately owned and operated facilities. Public nursing homes, however, constitute the clear majority in Denmark (85\%). Moreover, public as well as private nursing homes involve volunteers, and health assistants undergo the exact same training and educational experiences regardless of sector of employment. Hence, we have little reason to believe that our results would differ markedly for Danish private nursing homes.

\section{Implications}

Notwithstanding its limitations, our study offers a number of implications for public organizations and managers interested in involving volunteers in public service production. Drawing on psychological theory on stereotypes, one implication of stereotyped attitudes towards volunteers among service professionals may be that service professionals are more reluctant to cooperate with volunteers (Cuddy et al. 2011; see also Nesbit et al. 2018). Negative attitudes, including stereotypical views of volunteers as incompetent, may make volunteers feel less welcomed and appreciated in the organization, in turn increasing the likelihood volunteers exit the organization. (Nesbit et al. 2018). Previous research on stereotypes in workplace settings also suggest that awareness of other people perceiving one as incompetent may have negative effects on performance, in turn confirming the negative stereotypes (Roberson and Kulik 2007). Together, these different perspectives suggest that negative stereotypes on volunteer competence, as identified in our study, are likely to have detrimental effects on the involvement of volunteers and on service 
outcomes in public organizations. However, the effect of such stereotypes remains to be studied in future research.

So, what can public managers and practitioners do to avoid the formation of negative stereotypes of volunteers' competence among service professionals? Drawing on insights from the literature on stereotypes in workplace settings, one step to reduce negative stereotypes of volunteers is to articulate in a clear and concise way through organizational messages how volunteers are valued and may help their organization better serve its constituents and communities (Jensen 2018; Kray and Shirako 2012). Casting high-performing volunteers as role models may also serve to illustrate how volunteers can be successfully integrated into the organization, in turn reducing stereotypical views of volunteers' competence at large (Kray and Shirako 2012). Another beneficial step is to implement adequate volunteer management practices that ensure volunteers are properly trained to solve service tasks. Such practices could include screening, training and supervision of new volunteers (Hager and Brudney 2004; Rogelberg et al. 2010). We hope that future studies will engage the findings presented in this study by replicating them in other contexts (e.g., in other professional contexts, other types of services, and in other countries), but also by beginning to shed light on whether and how volunteer management practices and their interplay with organizational characteristics may help reduce the use of stereotypes towards volunteers among service professionals.

\section{Notes}

${ }^{1}$ Our results are also robust when we estimate treatment effects with ordered logit regression instead of OLS. These results are not shown, but are available upon request to the corresponding author.

${ }^{2}$ Detailed results can be obtained from the corresponding author upon request. 
${ }^{3}$ Detailed results can be obtained from the corresponding author upon request

\section{References}

Aarhus Municipality. 2016. Frivillighedsundersøgelsen 2016. Aarhus, Denmark: Sundhedsstaben Sundhed og Omsorg. An electronic copy of the report can be obatined from the corresponding author.

Alford, John. 2009. Engaging Public Sector Clients: From Service-Delivery to Co-production. Houndmills, UK: Palgrave Macmillan.

Andersen, Lotte B., and Lene H. Pedersen. 2012. Public Service Motivation and Professionalism. International Journal of Public Administration 35(1): 46-57.

Andersen, Simon. C., and Thorbjørn S. Guul. 2019. Reducing Minority Discrimination at the Front Line - Combined Survey and Field Experimental Evidence. Journal of Public Administration Research and Theory 29(3): 429-44.

Bovaird, Tony. 2007. Beyond Engagement and Participation: User and Community Coproduction of Public Services. Public Administration Review 67(5): 846-60.

Baldwin, J. Norman. 1990. Public Versus Private Employees: Debunking Stereotypes. Review of Public Personnel Public Administration 11(1-2): 1-27.

Brandsen, Taco, and Marlies Honingh. 2016. Distinguishing Different Types of Coproduction: A Conceptual Analysis Based on the Classical Definitions. Public Administration Review 76(3): $427-35$.

Brudney, Jeffrey L. 1983. The Evaluation of Coproduction Programs. Policy Studies Journal, 12(2): 376-385.

Brudney, Jeffrey L. 1990. Fostering Volunteer Programs in the Public Sector. Planning, Initiating and Managing Voluntary Activities. San Francisco: Jossey-Bass Publishers. 
Brudney, Jeffrey L., and Beth Gazley. 2002. Testing the Conventional Wisdom Regarding Volunteer Programs: A Longitudinal Analysis of the Service Corps of Retired Executives and U.S. Small Business Administration. Nonprofit and Voluntary Sector Quarterly 31(4): 525-48. Bullock, Alan, and Oliver Stallybass. 1977. The Fontana Dictionary of Modern Thought. Fontana Books.

Clary, E. Gil, Mark Snyder, Robert D. Ridge, John Copeland, Arthur A. Stukas, Julie Haugen, and Peter Miene. 1998. Understanding and Assessing the Motivations of Volunteers: A Functional Approach. Journal of Personality and Social Psychology, 74(6): 1516-30.

Cuddy, Amy J., Susan T. Fiske, and Peter Glick. 2007. The BIAS Map: Behaviors From Intergroup Affect and Stereotypes. Journal of Personality and Social Psychology 92(4): 631-48.

Cuddy, Amy J., Peter Glick, and Anna Beninger. 2011. The Dynamics of Warmth and Competence Judgments, and their Outcomes in Organizations. Research in Organizational Behavior 31: 7398.

De Boer, Noortje. 2020. How do Citizens Assess Street-level Bureaucrats' Warmth and Competence? A Typology and Test. Public Administration Review 80(4): 532-42.

Ellis, Susan J. 2010. From the Top Down: The Executive Role in Successful Volunteer Involvement. 3rd ed. Philadelphia: Energize Inc.

FOA. 2016. Frivilligt Arbejde på FOA Arbejdspladser. Copenhagen, Denmark: FOA Kampagne og Analyse https://www.foa.dk/ /media/faelles/pdf/rapporterundersoegelser/2016/frivilligt\%20arbejde\%20pdf.pdf [accessed December 16, 2021].

Fiske, Susan T., Amy J. Cuddy, and Peter Glick 2007. Universal Dimensions of Social Cognition: Warmth and Comptence. Trends in Cognitive Sciences 11(2): 77-83.

Fiske, Susan T. 2018. Steoretype Content: Warmth and Competence Endure. Current Directions in Psychological Science 27(2): 67-73 
Fiske, Susan T., Amy J. Cuddy, Peter Glick, and Jun Xu. 2002. A Model of (Often Mixed)

Stereotype Content: Competence and Warmth Respectively Follow From Perceived Status and Competition. Journal of Personality and Social Psychology 82(6): 878-902.

Freidson, Eliot. 1988. Profession of Medicine: A Study of the Sociology of Applied Knowledge. Chicago: University of Chicago Press.

Freidson, Eliot. 2001. Professionalism. The Third Logic: On the Practice of Knowledge. Chicago: University of Chicago Press.

Hager, Mark A., and Jeffrey L. Brudney. 2004. Volunteer Management Practices and the Retention of Volunteers. Washington, DC: Urban Institute.

Harrits, Gitte. S. 2019. Stereotypes in Context: How and When do Street-level Bureaucrats use Class Stereotypes?. Public Administration Review 79(1): 93-103.

Harrits, Gitte S., and Marie Ø. Møller. 2014. Prevention at the Front Line: How Home Nurses, Pedagogues, and Teachers Transform Public Worry into Decisions on Special Efforts. Public Management Review, 16(4): 447-480.

Jamieson, Jeremy, and Stephen G. Harkins. 2011. Distinguishing between the Effects of Steoretype Priming and Stereotype Threat on Math Performance. Group Processes \& Intergroup Relations 15(3): 1-14.

Jensen, Ulrich T. 2018. Does Perceived Societal Impact Moderate the Effect of Transformational Leadership on Value Congruence? Evidence from a Field Experiment. Public Administration Review 78(1): 48-57.

Jilke, Sebastian, and Lars Tummers. 2018. Which Clients are Deserving of Help? A Theoretical Model and Experimental Test. Journal of Public Administration Research and Theory 28(2): 226-38. 
Jilke, Sebastian., Wouter Van Dooren, and Sabine Rys. 2018. Discrimination and Administrative Burden in Public Service Markets: Does a Public-Private Difference Exist?. Journal of Public Administration Research and Theory 28(3): 423-39.

Keiser, Lael R., Peter R. Mueser, and Seung-Whan Choi. 2004. Race, Bureaucratic Discretion, and the Implementation of Welfare Reform. American Journal of Political Science 48(2): 314-27.

Kray, Laura J., and Aiwa Shariko. 2012. Stereotype Threat in Organizations: An Examination of its Scope, Triggers, and Possible Interventions. In Stereotype Threat: Theory, Process, and Application, edited by Michael Inzlicht and Toni Schmader, 173-87. Oxford: Oxford University Press.

Krosnick, Jon A., and Donald R. Kinder. 1990. Altering the Foundations of Support for the President through Priming. The American Political Science Review 84(2): 497-512.

Lipsky, Michael. 1980. Street-level Bureaucracy: Dilemmas of the Individual in Public Services. New York: Sage.

Marvel, John. 2016. Unconscious Bias in Citizens' Evaluations of Public Sector Performance. Journal of Public Administration Research and Theory 26(1): 143-58.

Maynard-Moody, Steven W., and Micahel C. Musheno. 2003. Cops, Teachers, Counselors: Stories from the Front Lines of Public Service. Michigan: University of Michigan Press.

Ministry of Health Denmark. 2016. National Undersøgelse af Forholdene på Plejecentre. Copenhagen, Denmark: Sundheds- og Ældreministeriet. https://sum.dk/Media/6/1/Undersoegelse-af-forholdene-paa-plejecentre.pdf [accessed December 16, 2021].

Morrall, Peter. 2001. Sociology and Nursing: An Introduction. Psychology Press.

Mosher, Frederick. C. 1968. Democracy and the Public Service. New York: Oxford University Press. 
Murphy, Raymond. 1988. Social Closure-The Theory of Monopolization and Exclusion. Oxford, UK: Clarendon.

Nesbit, Rebecca, Robert K. Christensen, and Jeffrey L. Brudney. 2018. The Limits and Possibilities of Volunteering: A Framework for Explaining the Scope of Volunteer Involvement in Public and Nonprofit Organizations. Public Administration Review 78(4): 502-13.

Nesbit, Rebecca, Heather. Rimes, Robert K. Christensen, and Jeffrey L. Brudney. 2016. Inadvertent Volunteer Managers: Exploring Perceptions of Volunteer Managers' and Volunteers' Roles in the Public Workplace. Review of Public Personnel Administration 36(2): 164-87.

Parks, Roger B., Paula C. Baker, Larry Kiser, Ronald Oakerson, Elinor Ostrom, Vincent Ostrom, Stephen L. Percy, Martha B. Vandivort, Gordon P. Whitaker, and Rick Wilson. 1981.

Consumers as Coproducers of Public Services: Some Economic and Institutional Considerations. Policy Studies Journal 9(7): 1001-11.

Pedersen, Mogens J., Justin M. Stritch, and Frederik Thuesen. 2018. Punishment on the Frontlines of Public Service Delivery: Client Ethnicity and Caseworker Sanctioning Decisions in a Scandinavian Welfare State. Journal of Public Administration Research and Theory 28(3): $339-54$.

Percy, Stephen L. 1984. Citizen Participation in the Coproduction of Urban Services. Urban Affairs Review 19(4): 431-446.

Perry, James L. 2017. The 2017 John Gaus Award Lecture: What if we took Professionalism Seriously? PS: Political Science \& Politics 51(1): 93-102.

Roberson, Loriann, and Carol T. Kulik. 2007. Stereotype Threat at Work. Academy of Management Perspectives 21(2): 24-40.

Roberts, Jennifer, and Michael Dietrich. 1999. Conceptualizing Professionalism: Why Economics Needs Sociology. The American Journal of Economics and Sociology 58(4): 977-98. 
Rogelberg, Stephen G., Joseph A. Allen, James M. Conway, Adrian Goh, Lamarry Currie, and Betsy McFarland. 2010. Employee Experiences with Volunteers, Assessment, Description, Antecedents, and Outcomes. Nonprofit Management \& Leadership, 20(4): 423-43.

Rölle, Daniel. 2017. Mass Media and Bureaucracy-bashing: Does the Media Influence Public Attitudes Towards Public Administration? Public Policy and Administration 32(3): 232-58.

Rohmer, Odile, and Eva Louvet. 2018. Implicit Stereotyping against People with Disability. Group \& Intergroup Relation 21(1): 127-40.

Rostgaard, Tine, Ole H. Petersen, Ulf Hjelmar, and Yosef Bhatti. 2016. Vi har sammenlignet offentlige og private plejecentre - her er de små forskelle. https://www.denoffentlige.dk/vi-harsammenlignet-offentlige-og-private-plejecentre-her-er-de-smaa-forskelle [accessed December $16,2021]$.

Thomsen, Mette K., and Ulrich T. Jensen. 2018. Fagprofessionelles klassifikation af kerneopgaver og komplementære opgaver. Politica 50(3):345-63.

Thomsen, Mette K., and Ulrich T. Jensen. 2020. Service Professionals' Response to Volunteer Involvement in Service Production. Journal of Public Administration Research and Theory 30(2): 220-39.

Van de Walle, Steven. 2004. Context-specific Images of the Archetypical Bureaucrat: Persistence and Diffusions of the Bureaucracy Stereotype. Public Voices 7(1): 1-15. 
Figure 1 Experimental Design: Complementary and Core Tasks in Nursing Home Contexts

Pretext across all experimental conditions:

"The next questions concern how you experience the use of volunteers at your work place."

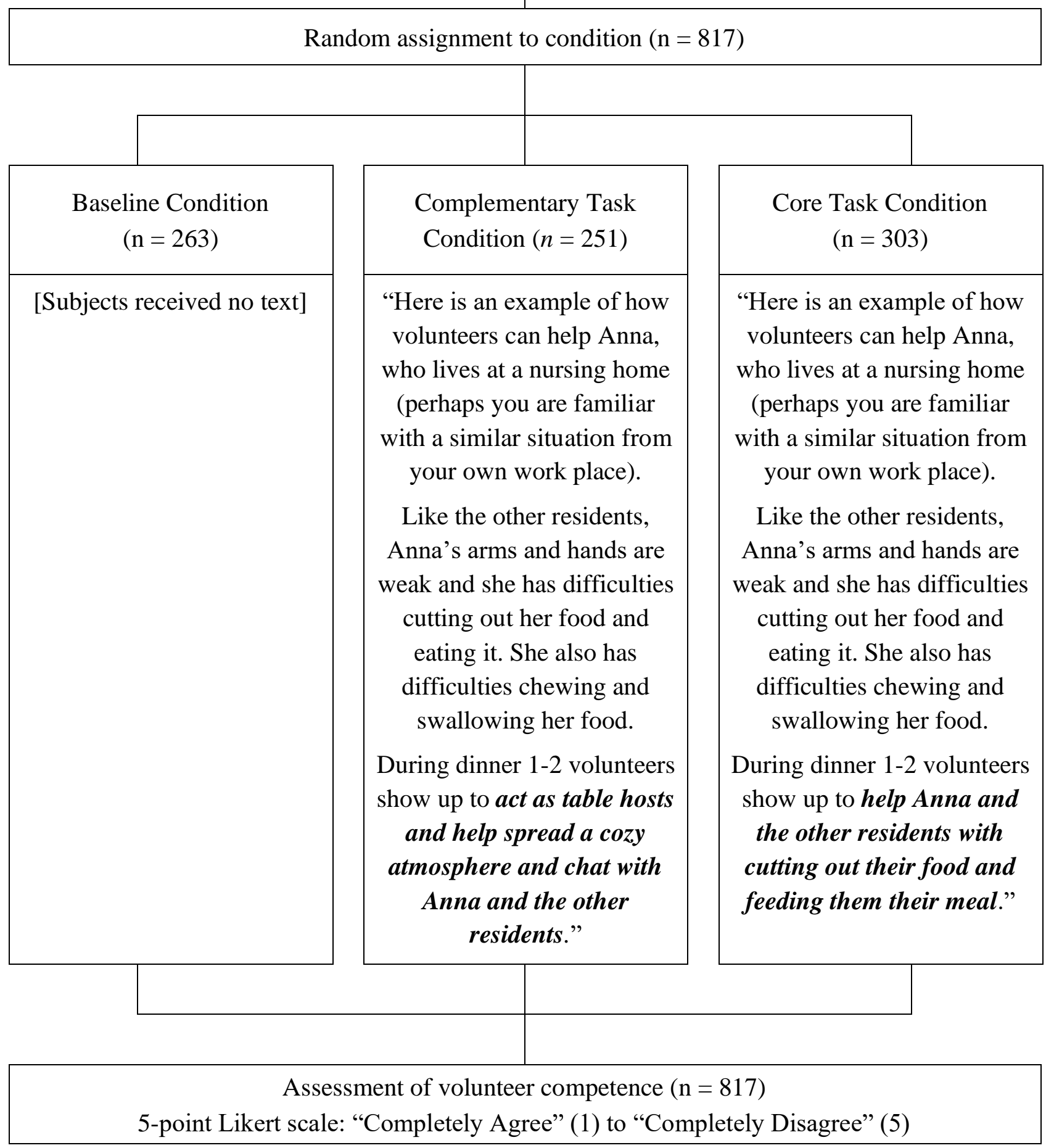


Table 1 Balance Check

\begin{tabular}{lcccc}
\hline & $\begin{array}{c}\text { Group 1: } \\
\text { Baseline Group }\end{array}$ & $\begin{array}{c}\text { Group 2: } \\
\text { Complementary task }\end{array}$ & $\begin{array}{c}\text { Group 3: } \\
\text { Core task }\end{array}$ & F-test $^{\mathrm{a}}$ \\
\hline${\text { Gender (female }=1)^{\mathrm{b}}}^{\mathrm{b}}$ & 0.98 & 0.98 & 0.95 & + \\
Age, years $^{\mathrm{b}}$ & 50.65 & 51.01 & 49.37 & n.s. \\
Education (health & 0.62 & 0.64 & 0.61 & n.s. \\
assistant, longer & & & & \\
education = 1) & & & 0.29 & n.s. \\
Region $(\text { Zealand }=1)^{\mathrm{b}}$ & 0.24 & 0.31 & 0.53 & n.s. \\
Employment hours $(<$ & 0.56 & 0.58 & & \\
37 hours/week $=1)^{\mathrm{c}}$ & & & 0.48 & n.s. \\
Shift (day shift $=1)^{\mathrm{c}}$ & 0.48 & 0.48 & 0.37 & n.s. \\
Work experience $(<5$ & 0.30 & 0.36 & & \\
years $=1)^{\mathrm{c}}$ & & & 303 & \\
\hline Observations & 263 & 251 & & \\
\hline
\end{tabular}

Note: Means for each treatment condition reported alongside mean for baseline group. ${ }^{\mathrm{a}} \mathrm{F}$-test of treatment indicators being jointly zero. + One of the p-values obtained in the F-test indicates a statistically significant difference in means between groups by experimental condition $(p<0.10)$. 'These data were obtained from FOA's web panel and merged with survey data after the data collection via a personal identifier. 'These data were obtained via the survey. A few respondents had either nonresponse or answered "don't know" on one of these items, and these are coded as " 0 ." 
Table 2 Average Treatment Effect of Priming Stimulus on Professionals' Judgement of Volunteer Competence. OLS Regression.

\begin{tabular}{|c|c|c|c|c|}
\hline & $\begin{array}{c}(1) \\
\text { Volunteer } \\
\text { competence }^{\mathrm{a}}\end{array}$ & $\begin{array}{c}(2) \\
\text { Volunteer } \\
\text { competence }^{\mathrm{a}}\end{array}$ & $\begin{array}{c}(3) \\
\text { Volunteer } \\
\text { competence }^{\text {b }}\end{array}$ & $\begin{array}{c}(4) \\
\text { Volunteer } \\
\text { competence }^{b}\end{array}$ \\
\hline \multicolumn{5}{|l|}{$\begin{array}{l}\text { Ref.: Baseline } \\
\text { group }\end{array}$} \\
\hline \multirow[t]{2}{*}{$\begin{array}{l}\text { Complementary } \\
\text { task }\end{array}$} & $-0.903 * * *$ & $-0.910 * * *$ & $-0.412 * * *$ & $-0.416 * * *$ \\
\hline & $(0.189)$ & $(0.190)$ & $(0.086)$ & $(0.087)$ \\
\hline Core task & $\begin{array}{c}-1.070 * * * \\
(0.181)\end{array}$ & $\begin{array}{c}-1.075^{* * *} \\
(0.182)\end{array}$ & $\begin{array}{c}-0.488 * * * \\
(0.082)\end{array}$ & $\begin{array}{c}-0.491 * * * \\
(0.083)\end{array}$ \\
\hline Constant & $\begin{array}{c}6.039 * * * \\
(0.132)\end{array}$ & $\begin{array}{c}5.851 * * * \\
(0.635)\end{array}$ & $\begin{array}{c}0.307 * * * \\
(0.060)\end{array}$ & $\begin{array}{c}0.221 \\
(0.290)\end{array}$ \\
\hline Observations & 817 & 817 & 817 & 817 \\
\hline $\begin{array}{l}\text { Adjusted R- } \\
\text { squared }\end{array}$ & 0.044 & 0.042 & 0.044 & 0.042 \\
\hline Covariates & $\mathrm{NO}$ & YES & $\mathrm{NO}$ & YES \\
\hline
\end{tabular}

Note: $* * * p<.001, * * p<0.01, * p<0.05$. OLS regressions with standard errors in parentheses.

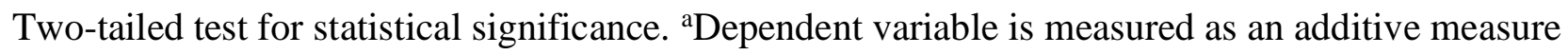
ranging from 0 to 10 . ${ }^{b}$ Dependent variable is standardized with standard deviation $=1$ and mean $=$ 0. Covariates: Variables listed in Table 1. 


\section{Appendix}

Table A-1 Overview of Data Sources in Study

\begin{tabular}{ll}
\hline Variables/measure & Source \\
\hline Demographic characteristics: gender, age, education and region & FOA's web panel \\
\hline Working conditions: employment hours, day shift and work experience & Electronic survey \\
\hline Outcome items: volunteer competences & Electronic survey \\
\hline Volunteer management practices & Electronic survey \\
\hline
\end{tabular}


Table A-2 Factor analysis: Items for Judgement of Volunteer Competence ${ }^{\text {a }}$

(1)

Factor 1

Most volunteers are competent to help citizens

0.80

De fleste frivillige er kompetente til at hjolpe borgerne

Volunteers are capable of considering citizens' need

Frivillige formår tilgodese borgernes behov

Volunteers often find it difficult to judge citizens' abilities (reversed)

0.45

Frivillige har ofte svart ved at vurdere borgernes evner

Observations 817

Note: Principal factor analysis; no rotation. Eigenvalue $=1.52$; Only one factor with eigenvalue $>1$. Cronbach's Alpha $=0.74$ for the three items. $\mathrm{N}=817$ observations. ${ }^{\text {aD }}$ Data on "volunteer competence" were obtained via the electronic survey. 
Table A-3 Comparison of Analytic Sample and FOA Members

\begin{tabular}{lcc}
\hline & $\begin{array}{c}\text { Health assistants } \\
(\text { Analytical sample) }\end{array}$ & $\begin{array}{c}\text { Health assistants } \\
(\text { FOA members) }\end{array}$ \\
\hline Gender (female) & $97 \%$ & $95 \%$ \\
Age & $0 \%$ & $0 \%$ \\
15-19 years & $3 \%$ & $8 \%$ \\
$20-29$ years & $16 \%$ & $16 \%$ \\
$30-39$ years & $18 \%$ & $23 \%$ \\
$40-49$ years & $43 \%$ & $36 \%$ \\
$50-59$ years & $19 \%$ & $16 \%$ \\
$60-$ years & $28 \%$ & $41 \%$ \\
Region (Zealand) & 817 & 27,375 \\
\hline Observations & & \\
\hline
\end{tabular}

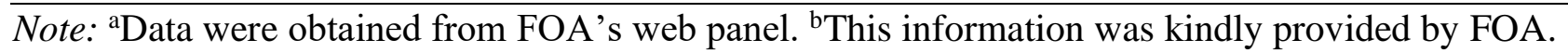


Table A-4.1 Volunteer Management Practices: Work Schedule

\begin{tabular}{|c|c|c|c|}
\hline \multicolumn{4}{|l|}{ Is there a work schedule for volunteers at your work? } \\
\hline Yes & No & Don't know & Total \\
\hline $9 \%$ & $65 \%$ & $27 \%$ & $100 \%$ \\
\hline
\end{tabular}

Note: 817 observations. 
Table A-4.2 Volunteer Management Practices: Guidelines for Volunteer Tasks

\begin{tabular}{|c|c|c|c|c|c|c|c|c|}
\hline \multicolumn{7}{|c|}{ There are clear agreements/guidelines for volunteer tasks at my work? } \\
\hline $\begin{array}{c}\text { Completely disagree } \\
\text { Completely agree }\end{array}$ & 2 & 3 & 4 & 5 & 6 & $\begin{array}{c}7 \\
\text { Complt know }\end{array}$ & Total \\
\hline $6 \%$ & $2 \%$ & $5 \%$ & $5 \%$ & $8 \%$ & $15 \%$ & $39 \%$ & $19 \%$ & $100 \%$ \\
\hline
\end{tabular}

Note: 817 observations. 


\section{Title Page}

Author 1 (corresponding):

Name: Ulrich Thy Jensen

Affiliation 1: School of Public Affairs, Arizona State University, United States

Affiliation 2: Crown Prince Frederik Center for Public Leadership, Aarhus University, Denmark

Email: ujensen@asu.edu

Postal address: 411 N. Central Ave., Suite 480, Phoenix, AZ-85004, United States

Bio: Ulrich Thy Jensen is an assistant professor in the School of Public Affairs, Arizona State University (ASU). He is also an affiliate of ASU's Center for Organization Research and Design and the Crown Prince Frederik Center for Public Leadership at Aarhus University. His research focuses on leadership, leadership development, and public management.

Author 2:

Name: Mette Kjærgaard Thomsen

Affiliation: Department of Political Science and Public Management, University of Southern Denmark, Denmark

Email: mtho@sam.sdu.dk

Postal address: Campusvej 55, 5230 Odense M, Denmark 
Bio: Mette Kjærgaard Thomsen is an associate professor in the Department of Political Science and Public Management at University of Southern Denmark. Her most recent research examines citizen coproduction, volunteering, service professionals' response to volunteering and administrative burdens. 